\title{
Offshore DC Grids as an Interconnection of Radial Systems: Protection and Control aspects
}

\author{
DraganJovcic \\ Mohsen Taherbaneh \\ University of Aberdeen, Aberdeen, UK
}

\author{
Jean-Pierre Taisne \\ Samuel Nguefeu \\ RTE, Paris, France
}

\begin{abstract}
This article presents a topology for DC grids which enables very robust DC fault protection with moderate costs, good operating flexibility and simple controls. It is postulated that radial DC systems are best suited for limited-size local DC grids. Radial topology enables robust and fast protection selectivity using only local signals and exploiting the advantages of hybrid DC circuit breakers. To enable flexible expansion options to national/international systems, it is suggested to interconnect star points of radial systems using DC/DC converters. DC/DC converters enable inherent isolation of $\mathrm{DC}$ faults and provide firewall between radial DC grids. Each interconnecting cable is protected by a DC/DC at one end and a hybrid Circuit Breaker at the other end. The control options for DC/DC converter and the radial grids are analysed. A detailed simulation model of 6 terminal DC grid with 2-star points is presented. The PSCAD simulation results confirm DC fault isolation and good control performance of the proposed topology for a range of DC fault contingencies.

Index Terms - DC power systems, DC power transmission, DC-DC power conversion, HVDC converters, HVDC transmission, Wind Energy.
\end{abstract}

\section{INTRODUCTION}

The development of DC transmission grids is among the most significant technical challenges in power engineering. With the interest in offshore wind power and advances in modular multilevel VSC converters, there is growing demand for developing HVDC grids. The backbone of future European super grid will be constructed based on DC grid [1].

Currently only point to point HVDC exist in many installations worldwide. The DC grids are built by interconnecting multiple DC transmission lines, however, the topologies, protection and operating methods are still uncertain. As DC cables have very small impedance without any reactance $(f=0)$, the DC faults will cause widespread voltage collapse in the grid and the fault currents will be large. DC grid fault current interruption should happen on the rising slope i.e. before fault current reaches steady-state which gives only few $m s$ for protection action [2].

Fast and low loss hybrid DC CBs (Circuit Breakers) have been developed recently [3]. The cost of these units will be of the order of $30 \%$ of VSC converter costs and the losses are negligible. However prototypes have been demonstrated as an isolated component only. As a single unit with a local current sensor these DC CBs can reliably clear DC faults within

This project is funded by RTE.

D Jovcic and $M$ Taherbaneh are with University of Aberdeen, Aberdeen, AB24 3UE, U.K.(d.jovcic@abdn.ac.uk, m.taherbaneh@abdn.ac.uk).

J.P Taisne and S. Nguefeu are with RTE: Coeur Defense, 92932 Paris, France ( jean-pierre.taisne@rte-france.com, samuel.nguefeu@ rte-france.com ) 2-5msassuming that interrupting current is not above 5-10kA. There is no realistic possibility for significantly increasing further the semiconductor interrupting current capability.

A DC-grid wide protection system is the next unresolved and probably the most significant technical challenge. The main difficulty is the protection selectivity in large grids and within very short time period of $2-5 \mathrm{~ms}$. Some promising DC grid protection approaches have been reported [4]-[6]. The differential protection method in [4] is accurate but requires several milliseconds communication delay between DC CBs and perhaps more in case of long DC cables. Any delay in fault clearing implies that fault current continues to increase. The practical rating of $\mathrm{DC} \mathrm{CBs}$ and costs will therefore limit the length of DC lines and the number of DC lines that can feed DC fault (i.e. DC fault level). The traveling wave detection method in [5] and the DC grid zoning in [6] do not require communication but may not be able to offer high accuracy considering low DC impedances and very short decision time.

It will be very challenging to achieve high DC power transfer security (comparable to AC transmission) if meshed DC grid topologies are adopted and DC CBs are used solely as protection means.

The use of DC/DC converter as a DC circuit breaker has been proposed [7]-[9]. DC/DC converters enable ideal isolation of two DC systems since they will not propagate DC faults. They can also connect DC systems of different DC voltage levels and with different DC technologies. However DC/DC converters have approximately $180-200 \%$ VSC converter costs and also the operating losses of around $2 \%$ should be considered. Clearly DC/DC converters cannot be used for isolation all cables in meshed DC grids.

Reference [10] presents a comprehensive cost comparison of DC grid topologies. The conclusions are derived solely on the cost and operational basis but practical aspects of protection system are not evaluated in depth. Additional limitation of the study is that the size of considered systems is modest.

With traditional AC transmission systems the grid topology is determined based on the costs and operational priorities, with the understanding that protection system can be developed later using standard approaches. In case of DC grids we may need to consider topology and protection system in parallel from the earliest stages. In the current study we focus on developing DC grid topology which will facilitate reliable protection system within the DC CB component constraints.

The aim of the study is to develop building principle for DC grids of any complexity (any number of terminals and geographical size) and with highly reliable protection. The proposed DC grids will be tested on a 6-terminal DC grid test system using a detailed PSCAD simulation model. 


\section{RADIAL DC GRIDS}

\section{A. Protection method}

The main purpose of a DC grid (connecting numerous VSC terminals) is to provide opportunity for each terminal to trade power with any other terminal. Depending on the topology the costs, losses, operating flexibility and power security will vary.

The main purpose of the grid protection system is to rapidly isolate the smallest grid segment in case of a DC fault, in order to enable uninterrupted operation of the remaining part of the grid. Depending on the topology there will be more or less loss in capacity in the post-fault topology.

A radial DC grid has a single star point connecting VSC terminals with radial DC cables as shown in Fig. 1. There is no terminal to terminal connection. This topology is not normally used with $\mathrm{AC}$ transmission but they are common in distribution systems and it has other operational and cost advantages and disadvantages which are studied in [10].

The main disadvantage is the loss of capacity (one VSC terminal) for a DC cable fault. This problem can be limited by restricting the size of VSC converter within the maximum power loss criterion according to national grid codes (1800MW in UK). The redundancy can be achieved by adding a new radial cable with a VSC (not just a cable as with meshed AC grids), connecting to the star point.

This topology has a very important advantage since it enables development of a simple, accurate and robust grid protection system. Each DC cable can be isolated from the grid using a single DC CB located at the star point DC bus.

Fig. 1 shows the radial DC line protection system, where the given numerical values are used in the model in section IV. The protection consists of a $\mathrm{DC} \mathrm{CB}$, a current sensor and a controller. A trip decision is made if the local current sensor detects current over a threshold (set at $4 k A$ in the test system) and in positive direction. Only the local sensor is used to make trip decision. The selectivity is therefore very simple and robust. For any DC fault only one DC $\mathrm{CB}$ sees a positive current (all other DC CBs see negative current, as shown by red lines). This is significant advantage over meshed DC grids.

Since there is no communication with any other component, the protection can operate as fast as hardware dynamics and processing speed will allow. The studies in [2] indicate that hybrid DC CBs could be operated within $2 \mathrm{~ms}$.

At the other end, the cable is isolated using a conventional $\mathrm{AC} \mathrm{CB}$ as with any HVDC system. The mechanical AC CB will have operating time one order of magnitude slower (20-50ms), but this has no implication for DC grid.

The radial DC lines can be of any length since there is no need for communication along DC lines.

Any number of DC cables (terminals) can be connected to the star point, but the steady-state fault level is dependent on the number of DC lines. Nevertheless the steady-state fault level may not be limiting factor since fast DC CBs will interrupt the current on a rising slope. Consider the worst case of infinitely strong $320 \mathrm{kV}$ DC system which gives infinite steady-state fault current. The DC fault current rise equation is:

$$
L_{C B} \frac{\Delta I}{\Delta t}=V_{D C}
$$

where $L_{C B}$ is the series reactor inside $\mathrm{DC} \mathrm{CB}, \Delta t$ is the operating time and $\Delta I$ is the fault current increase from the load current. Assuming $\Delta t=3 \mathrm{~ms}$ and $\Delta I=7 \mathrm{kA}$ we get the requirement for $L_{C B}=137 \mathrm{mH}$. This is a reasonable inductor size which is in agreement with [2] indicating that there is no practical limit on the number of DC lines inside the radial DC grid.

The above protection strategy is applicable only to radial topologies with a single star point, and clearly cannot be used with meshed DC grid. The selectivity becomes an issue if any additional DC CB sees positive current during DC faults.

\section{B. Back up protection options}

Fig. 2 shows the radial system with a back up protection. A split bus is introduced with two bus-bar DC CBs (DC CB B1_A and DC CB B1_B). Note that DC CBs are unidirectional, and a bidirectional component can have a common inductor only. In case that DC CB1 fails to operate for a preset time interval, then DC CB B1_B and AC CB2 would open with a larger loss in capacity, i.e. loss of terminals 1 and 2 .

The failure modes of hybrid DC CB are not yet clear, but it is known that all semiconductor switches have a driver-level hard-wired overcurrent protection.This internal switch self-protection is inaccurate and inaccessible to control but it is very robust and reliable since the complete logic including the sensor is at the valve assembly. It is proposed that this switch self-protection can also be used as last-defense option for DC grid back up protection. Fig. 3 shows the topology of hybrid DC CB [8]. The normal load current path is through the mechanical $\mathrm{CB}$ and the auxiliary valve. In case of protection system failure, there will be very large current through this path. This large current will activate the driver-level hard-wired overcurrent protection in the auxiliary valve of DC CB1. The auxiliary valve IGBT will open immediately interrupting thus the fault current. Nevertheless the auxiliary valve will see large open circuit voltage (full DC voltage) which is much larger than its blocking forward capability. The overvoltage will destroy IGBTs which are configured to fail in open circuit. This back-up protection method therefore does not require any additional DC CBs and the loss of capacity is minimal. On the downside, this implies destruction of a DC CB. Note that all other DC CBs will see large negative which will be conveyed by their diodes and which have better overcurrent capability.

Therefore considering the cost of additional DC CBs it is not clear if grid operators will demand full additional back up protection systems. Back up protection is not considered further in this study.

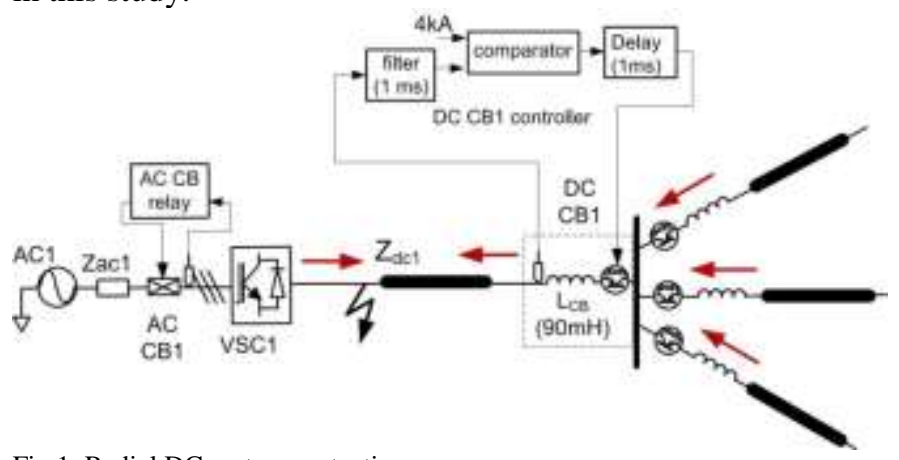

Fig.1. Radial DC system protection 


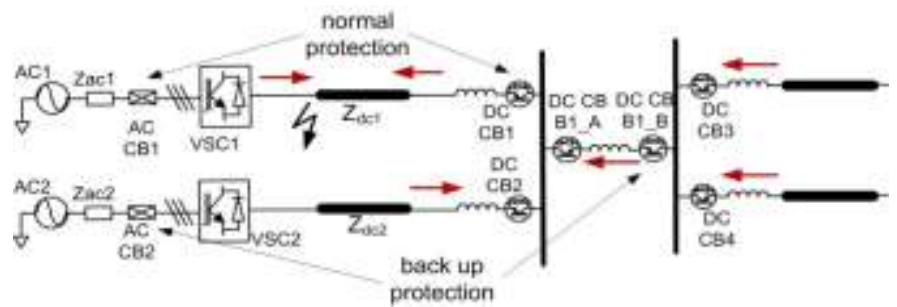

Fig.2. Radial DC system with back up protection based on split bus.

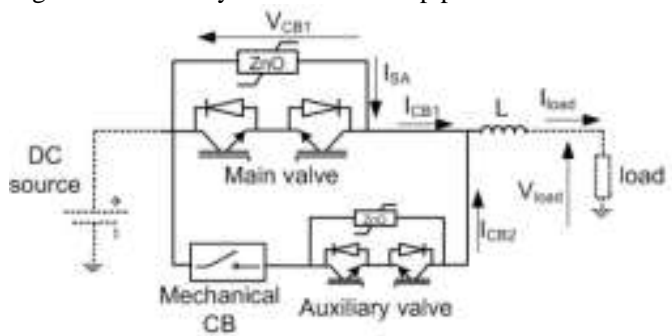

Fig.3. Hybrid DC Circuit Breaker.

\section{INTERCONNECTING RADIAL DC SYSTEMS INTO A LARGE DC GRID}

\section{A. Topology and protection}

A single radial DC grid will not be adequate as the geographical area increases. Even in smaller geographical area, increasing number of terminals will call for another star point because of reliability reasons.

It is proposed in this study to interconnect the star-points of different radial systems using DC/DC converters. Each interconnecting cable has a DC/DC converter at one end and a
DC CB at the other end, as shown for a 21-terminal DC grid in Fig. 4. The main reasons for using DC/DC converters are:

- They inherently prevent DC fault propagation. A fault at one radial system will be seen as open circuit at the other system. No communication or fast control is required.

- They enable different DC voltages at the two radial systems.

- They facilitate power control in the interconnecting cable.

- The two radial systems become decoupled and therefore different technologies, control and protection (different vendors) can be used.

On the downside, DC/DC converters have high costs and the on-state losses. Fig. 5 shows high power DC/DC converter from [8] but other topologies can also be used.

In a DC grid of $n_{t}$ terminals, the costs and operational priorities will determine the number of star points $n_{s}$. Then, the number of DC/DC converters will be $n_{s}$, while the total number of DC CBs will be $n_{t}+n_{s}$. Expansion of DC grid is simple. A new VSC terminal requires a radial cable with DC CB connecting to the nearest star point. A new interconnecting cable requires additional DC/DC converter and one DC CB.

Although individual DC/DC cost is high, the total cost of a DC grid is comparable with other topologies, as shown in the following example. Table 1 shows the total DC grid component rating for the 21-terminal test system in Fig. 4, where base is the VSC converter rating (all VSC have the same rating). Also, each DC CB has $0.3 p u$ rating corresponding to the VSC on the same DC line [7]. Considering very fast operation in radial systems, DC CB rating is not sensitive to fault level. A DC/DC

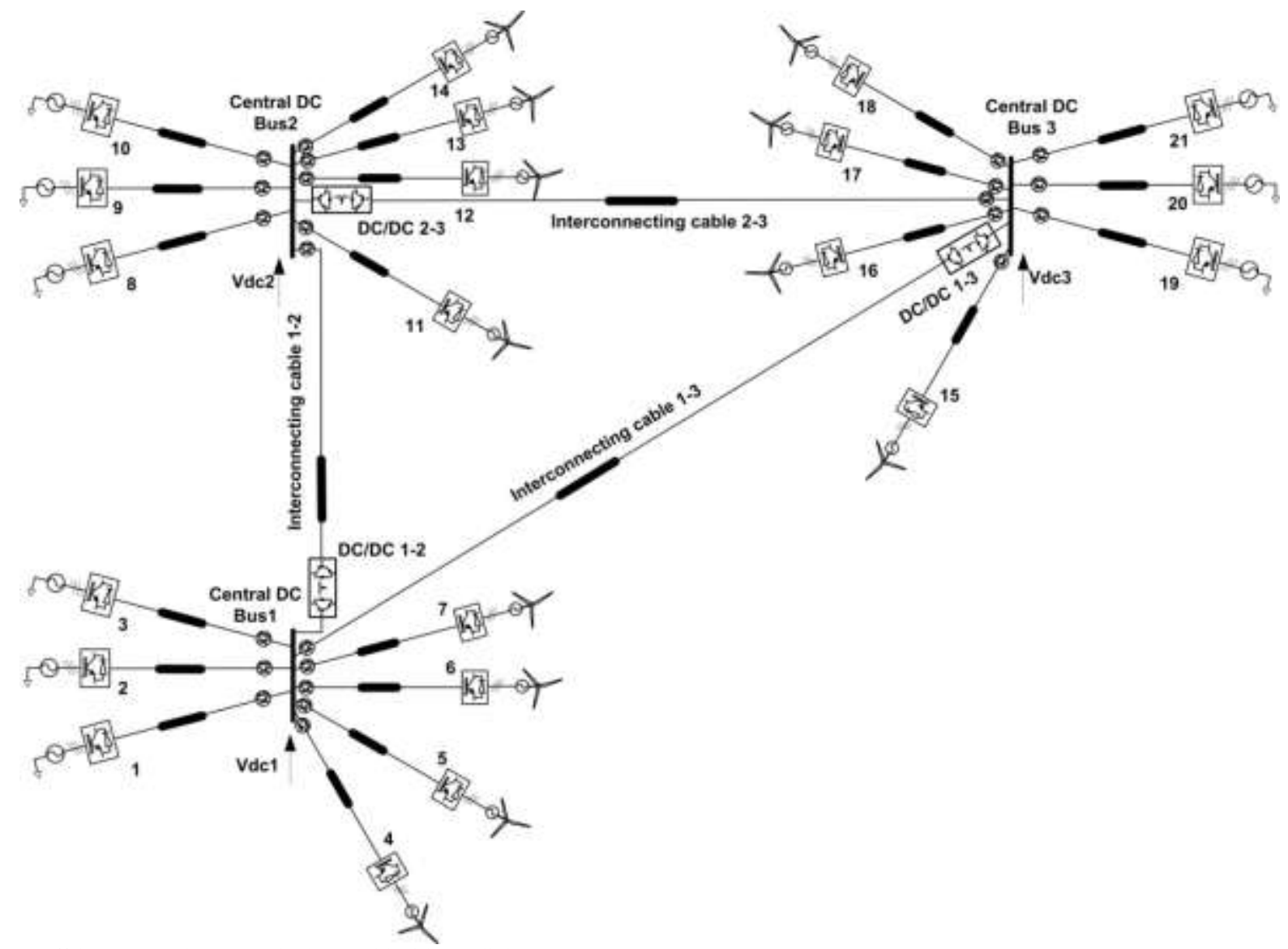

Fig.4. 21 (12 offshore +9 onshore) terminal DC grid with 3 radial DC systems. 
converter consists of two VSCs and therefore the rating is $2 p u$. As a comparison, using a ring DC grid topology we would need 2 DC CBs at each DC cable and the total cost becomes similar as shown in Table 1. Note also that the ring topology would require much larger rating for many cables and probably for DC CBs because of the protection delays. The operational and cost comparisons between topologies are given in depth in [10] and are not elaborated further.

\begin{tabular}{|l|l|l|}
\multicolumn{2}{|c}{ TABLE 1 COMPONENTS FOR 21 TERMINAL DC GRID } \\
\hline & Interconnected Radial Grid & Ring Grid \\
\hline DC CB & $24 \times 0.3 \mathrm{pu}=7.2 \mathrm{pu}$ & $42 \times 0.3 \mathrm{pu}=12.6 \mathrm{pu}$ \\
\hline DC/DC & $3 \times 2 \mathrm{pu}=6 \mathrm{pu}$ & 0 \\
\hline total & $13.2 \mathrm{pu}$ & $12.6 \mathrm{pu}$ \\
\hline
\end{tabular}

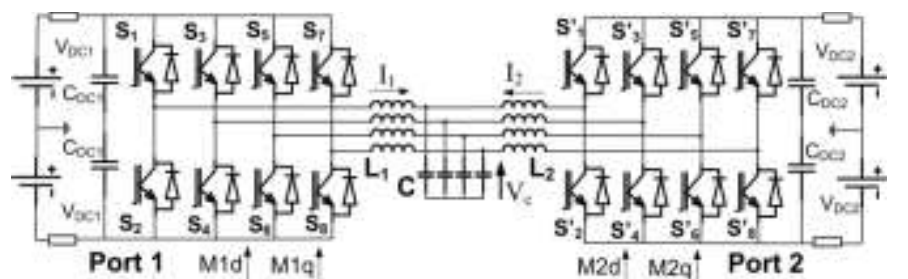

Fig.5. 4-phase DC/DC converter

\section{B. Grid control}

Each radial DC grid is considered as a separate system for control development. This simplifies controls and provides safeguard against spreading of instabilities and blackouts. Each DC terminal controls local power with additional DC voltage droop feedback as it is common practice in DC grids [11].

The proposed controller for DC/DC converter is shown in Fig. 6. At the inner most control level there is current $d$ and $q$ components control which prevent semiconductor overcurrents. The middle control layer regulates active and reactive power at each port. The port 2 balances power by keeping coordinate frame aligned with the capacitor voltage $\left(V_{c q}=0\right)$, where an in-depth analysis of DC/DC converter design and modeling is given in [8]. The DC/DC converter regulates the power in the interconnecting cable at the value $P_{\text {dcdcrefo }}$ which is determined by the DC grid dispatcher.

It is proposed that the power reference is moderated with DC voltage droop feedback from both DC grids $\left(V_{d c l}\right.$ and $\left.V_{d c 2}\right)$. The two grids are practically decoupled and disturbances normally occur on only one radial grid at a time. The DC/DC converter in this way draws power from a healthy grid in order to stabilize a grid under disturbance. The radial DC grid will see DC/DC converter as any other VSC terminal.

An alternative control method is to use DC voltage control for DC/DC converter. In case of small grids this method will imply significant coupling between the two DC grids and possible frequent DC/DC converter saturation. However in case of large systems with many terminals such control method may become attractive as a stand-alone control for an embedded DC/DC converter.

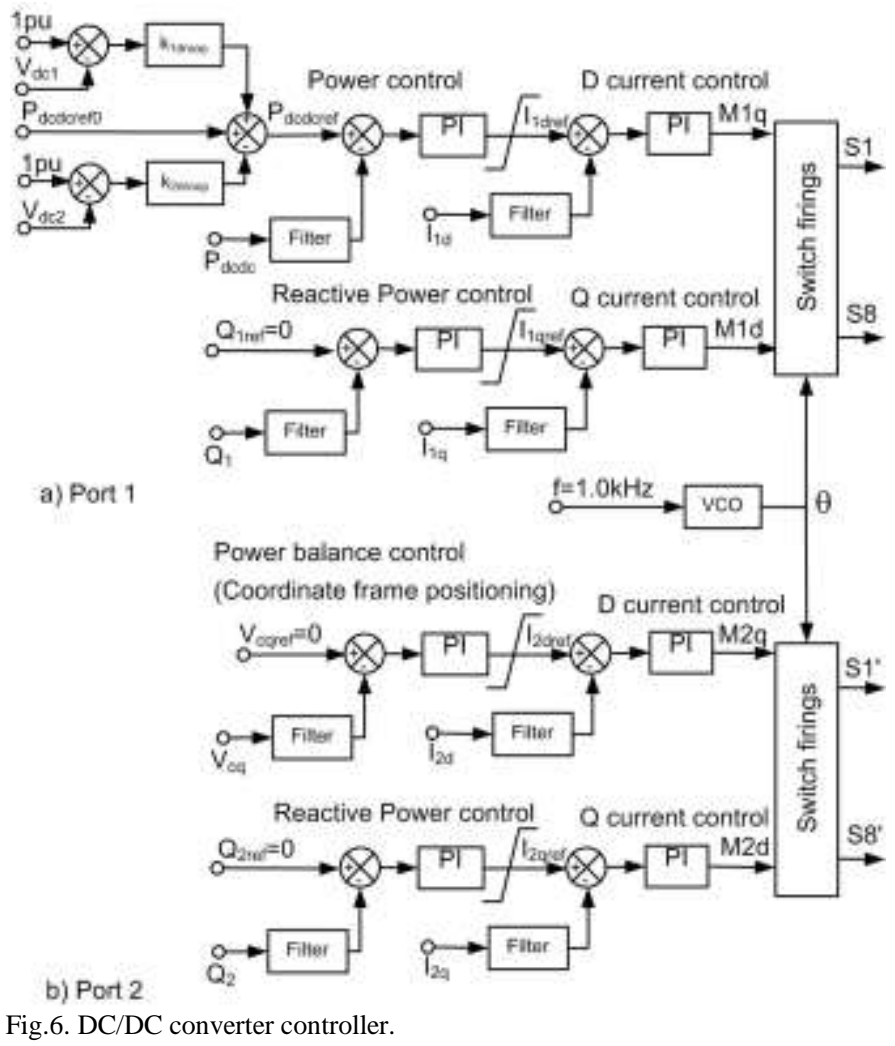

\section{Simulation VerificAtion}

\section{A. Test system}

The test system is shown in Fig. 7. It consists of two, 3-terminal radial grids. Each radial grid has two on-shore $1 G W$ VSC terminals and one offshore $1 G W$ wind farm. Such star topology resembles the UK East HVDC Interconnector and other first-stage European DC grid projects (COBRA cable) which are being studied. All the component ratings and steady-state power flows are shown in Fig. 7. The DC voltage levels at the two star systems are purposely selected to be different in order to demonstrate the flexibility of the topology.

The DC/DC converter test system data are shown in table 2 in the Appendix. Although 2-phase converter is studied as least cost option in [8], the high power converters will require more phases because of semiconductor rating limitations. A four phase topology is therefore selected to eliminate ground harmonics currents and also to improve reliability (tripping a phase enables $3 / 4$ power transfer).

The $1 G W$ wind farms are modeled in detail as a single equivalent variable speed machine by scaling up detailed $5 M \mathrm{~W}$ Permanent Magnet Synchronous Generator machine model as presented in [12]. The VSC converters and controls use standard representation according to [11] or [12]. All the controls are modeled in full detail (including all PLLs) but converters use average non-linear models. The converter and AC system data are given in the Appendix, in Tables 2 and 3. The AC systems have short circuit ratio of 30 with $X / R=10$. 


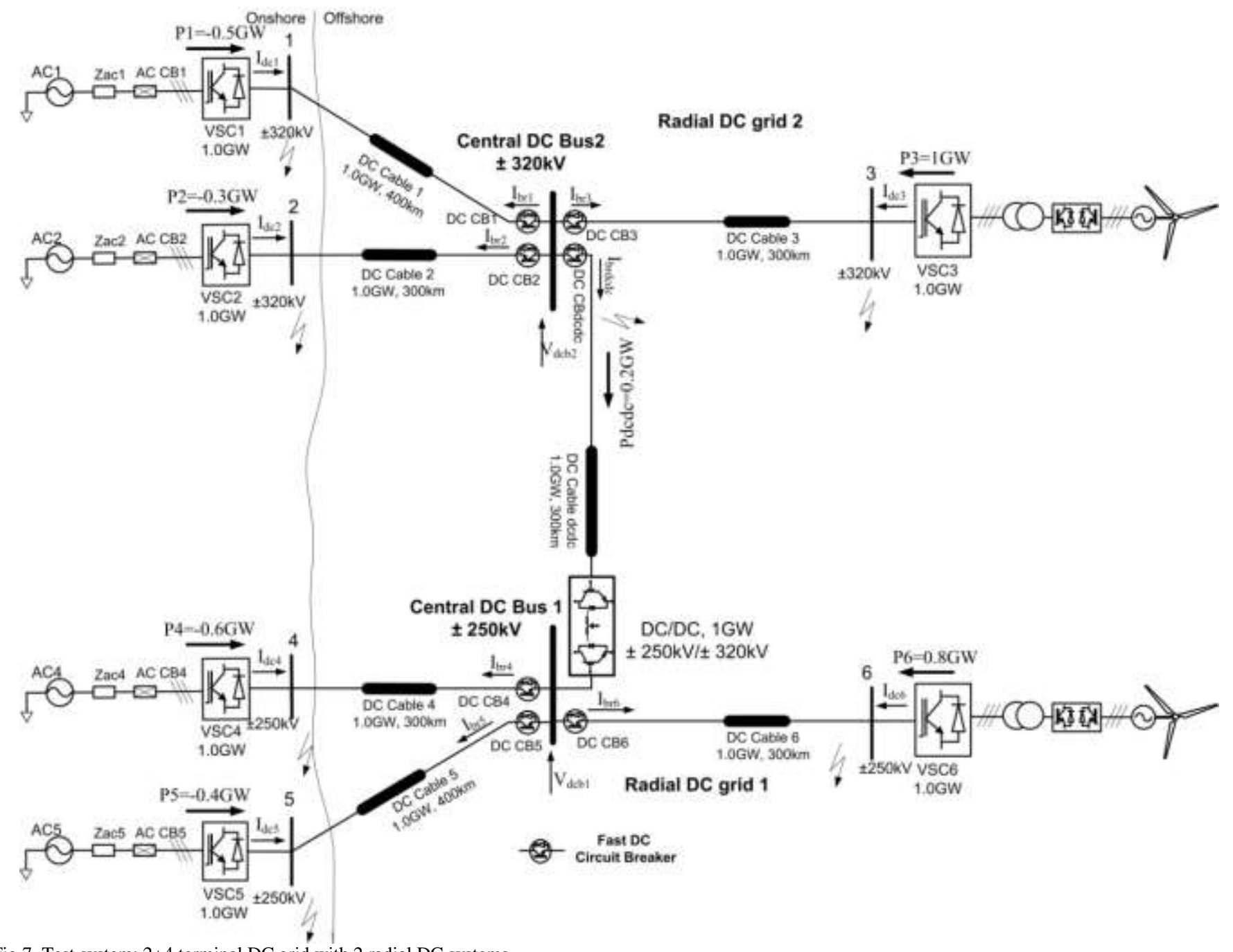

Fig.7. Test system: 2+4 terminal DC grid with 2 radial DC systems.

One terminal in each star-grid (VSC1 and VSC5) is set to control DC voltage, as it would be normal practice with small DC grids. The remaining onshore VSCs (VSC2 and VSC4) control local power with DC voltage droop feedback. The wind farm VSC converters inject all the available wind power and have no contribution to DC grid control (no droop feedback).

The DC cables are modeled in detail using frequency dependent distributed parameter model from PSCAD library. The complete model is built on PSCAD platform.

The protection system model is developed for each DC cable as shown in Fig. 1. Each DC CB is modeled as an ideal switch with $90 \mathrm{mH}$ series reactors.

Fig. 7 indicates all the DC fault locations that are studied. In all cases the system operates in steady-state shown in Fig. 7, and at $3 s$ a pole-pole zero-impedance DC fault is applied. Also small signal disturbances are tested but they give less control challenges and for lack of space they will not be shown.

\section{B. DC Fault on a radial cable}

Fig. 8, 9 and 10 show system response following a permanent pole-pole fault at DC terminals of VSC 4. In Fig. 9 we can see that DC CB4 interrupting current is $8 k A$. The remaining two DC CBs on the same star grid (DC CB5 and DC CB6) see negative current and therefore selectivity is very simple. On the terminal side the faulted cable is isolated by AC CB4 according to standard practice with HVDC DC fault management (not shown for brevity).

The top 3 graphs in Fig. 9 confirm that circuit breakers on grid 2 do not see any notable current disturbance. Fig. 10 shows actual DC CB current around the fault instant and illustrates the operating delays. The finally selected $90 \mathrm{mH}$ reactor gives acceptable peak current of around $8 \mathrm{kA}$. A reactor of $40 \mathrm{mH}$ gives around $15 \mathrm{kA}$ peak current which would be beyond the switch turn off capability.

Fig. 8 illustrates that terminal 5 rapidly increases power in order to maintain local DC voltage at $1 p u$. A particular concern with radial grids is the star point voltage which cannot be directly controlled. The simulations however show that the star point DC bus 1 voltage $\left(V_{d c b l}\right)$ is well bounded even for most series contingencies. In Fig. 8 it settles at slightly higher value since cable 4 has different resistance from cable 5 . It is seen that DC/DC converter reacts to $V_{d c b l}$ increase by reducing the power transfer. The top graph in Fig. 8 confirms that grid 2 is not affected by this significant outage on grid 1. VSC2 converter gradually increases power transfer to compensate for the $\mathrm{DC} / \mathrm{DC}$ converter power reduction. 

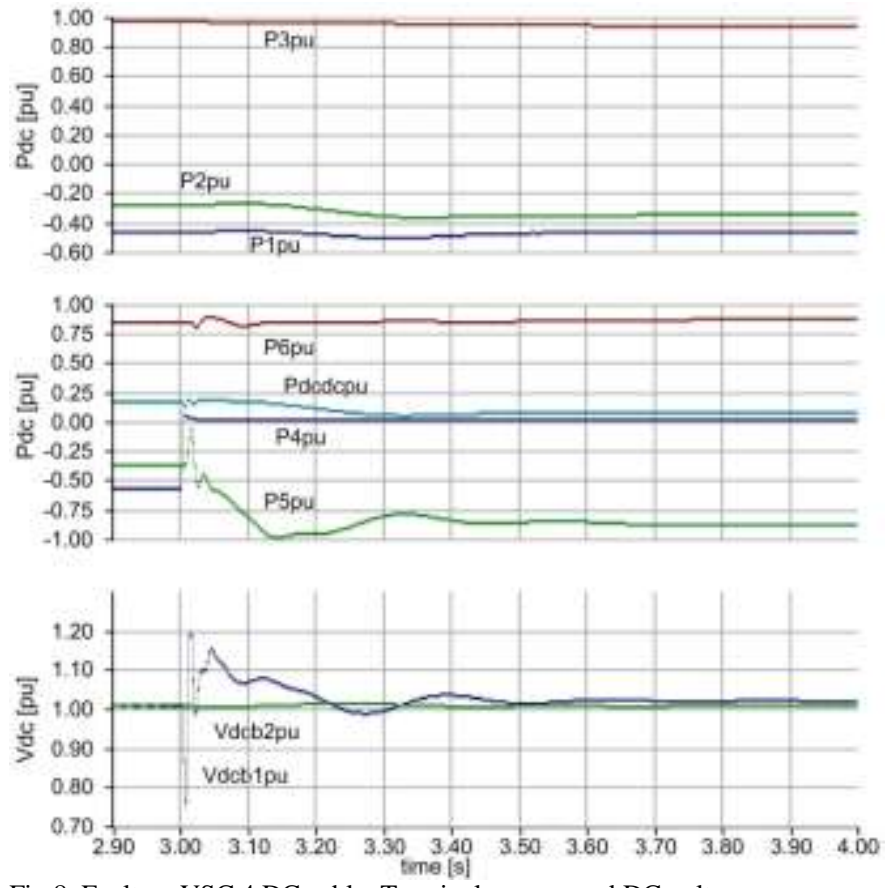

Fig.8. Fault on VSC 4 DC cable. Terminal powers and DC voltages.
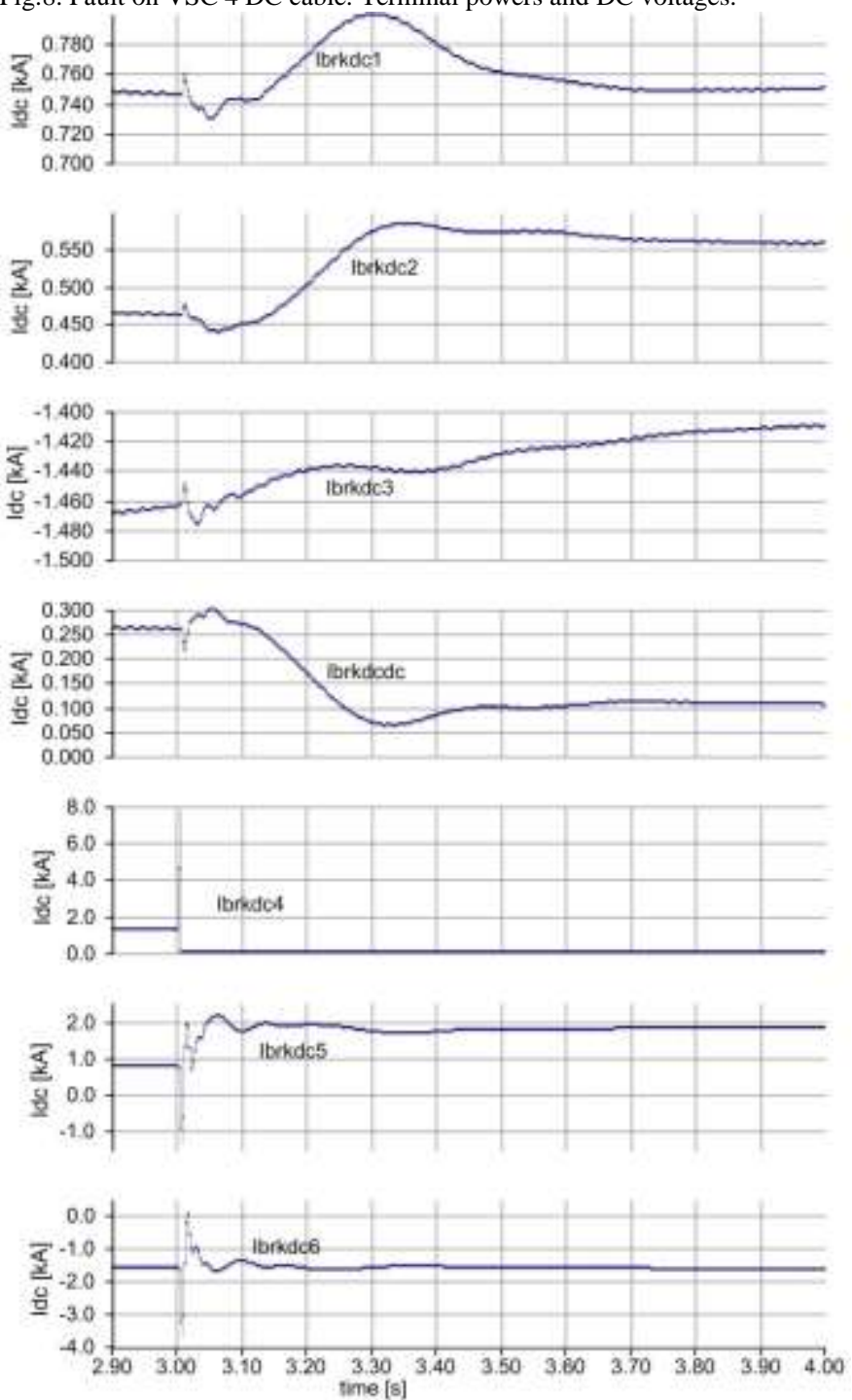

Fig.9. Fault on VSC 4 DC cable. Currents in 7 DC CBs.

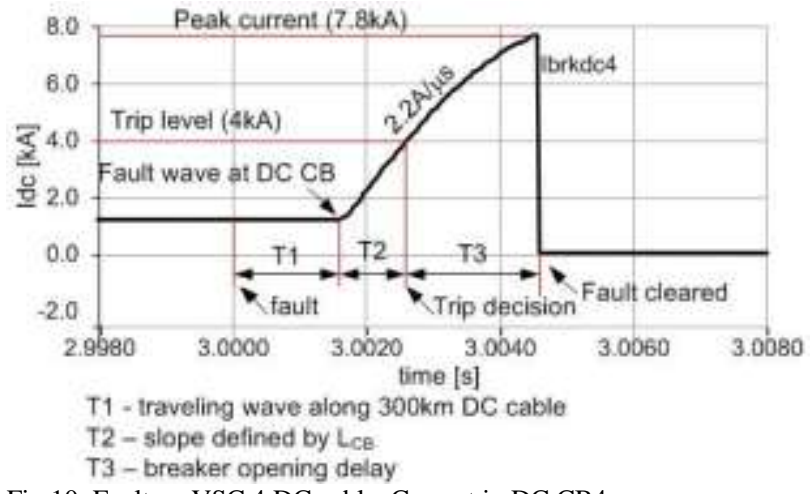

Fig.10. Fault on VSC 4 DC cable. Current in DC CB4.

\section{C.DC Fault on the interconnecting cable}

Fig. 11, 12 and 13 show the system responses for a permanent pole-pole DC fault at DC bus 2 terminals of the interconnecting $d c d c$ cable.

It is observed in Fig. 12 that $D C C B d c d c$ has interrupting current of around $8.5 \mathrm{kA}$. This is slightly higher current than in case of fault on DC cable 4 since there is now fault current infeed from 3 VSC converters. It is also seen in the lower 3 graphs of Fig. 12 that DC Cbs in grid 1 do not see large currents.

Fig. 11 shows that VSC1 and VSC2 are able to establish a stable post-fault power flow and that grid 2 DC voltage deviations are limited. It is also seen that grid 1 only sees gradual loss of DC/DC infeed which confirms that DC/DC converter will not transfer DC fault.

Fig. 13 shows the internal DC/DC converter variables which is of interest since this is worst-case fault at high-voltage $\mathrm{DC} / \mathrm{DC}$ terminals. It is seen that:

- Before the fault DC/DC converter operate satisfactory with power at reference point, $V_{c q}=0$, and reactive powers at each port equal to zero.
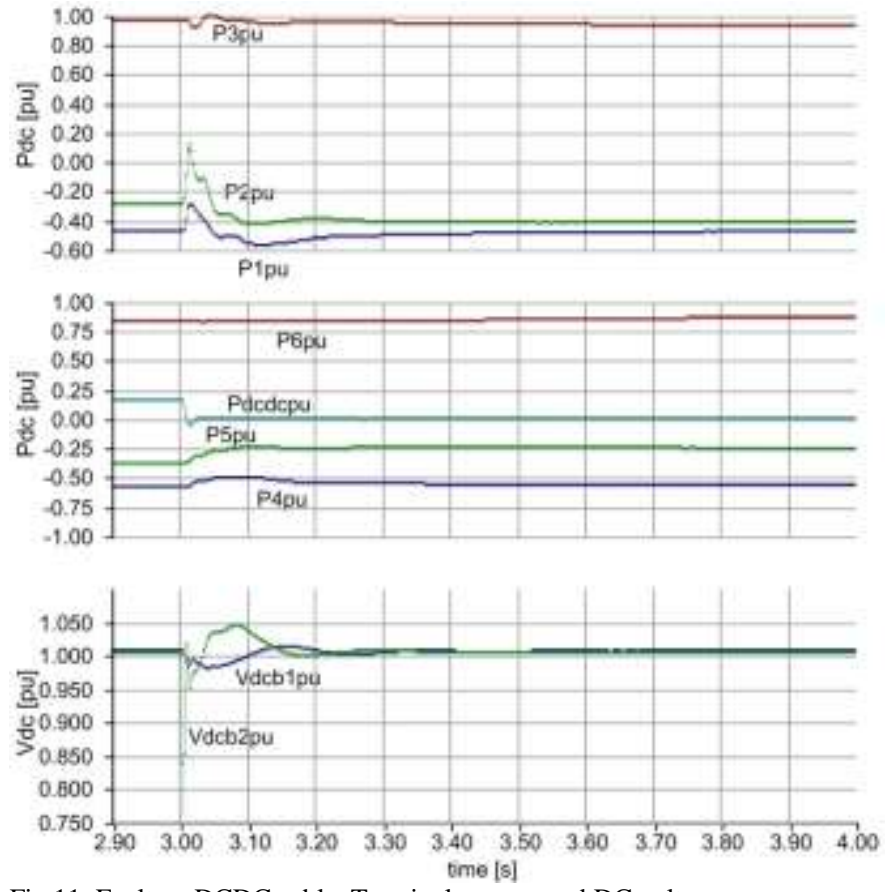

Fig.11. Fault on DCDC cable. Terminal powers and DC voltages. 
- During the fault $(3 s-3.27 s)$ the converter naturally responds by reducing currents and there are no transient overcurrents. No special controls are required.

The permanent fault is detected by low DC voltage for a preset time interval (around 250ms) and DC/DC converter is tripped by blocking IGBT pulses (at $3.27 \mathrm{~s}$ ). This permanently isolates $d c d c$ cable from the DC grid 1 .

All the DC CBs employ $90 \mathrm{mH}$ reactor which introduce lags and slows the system dynamics, comparing with conventional VSC HVDC. The authors did not see need for special controls in the test system, however in case of very large systems further dynamic studies will be required.
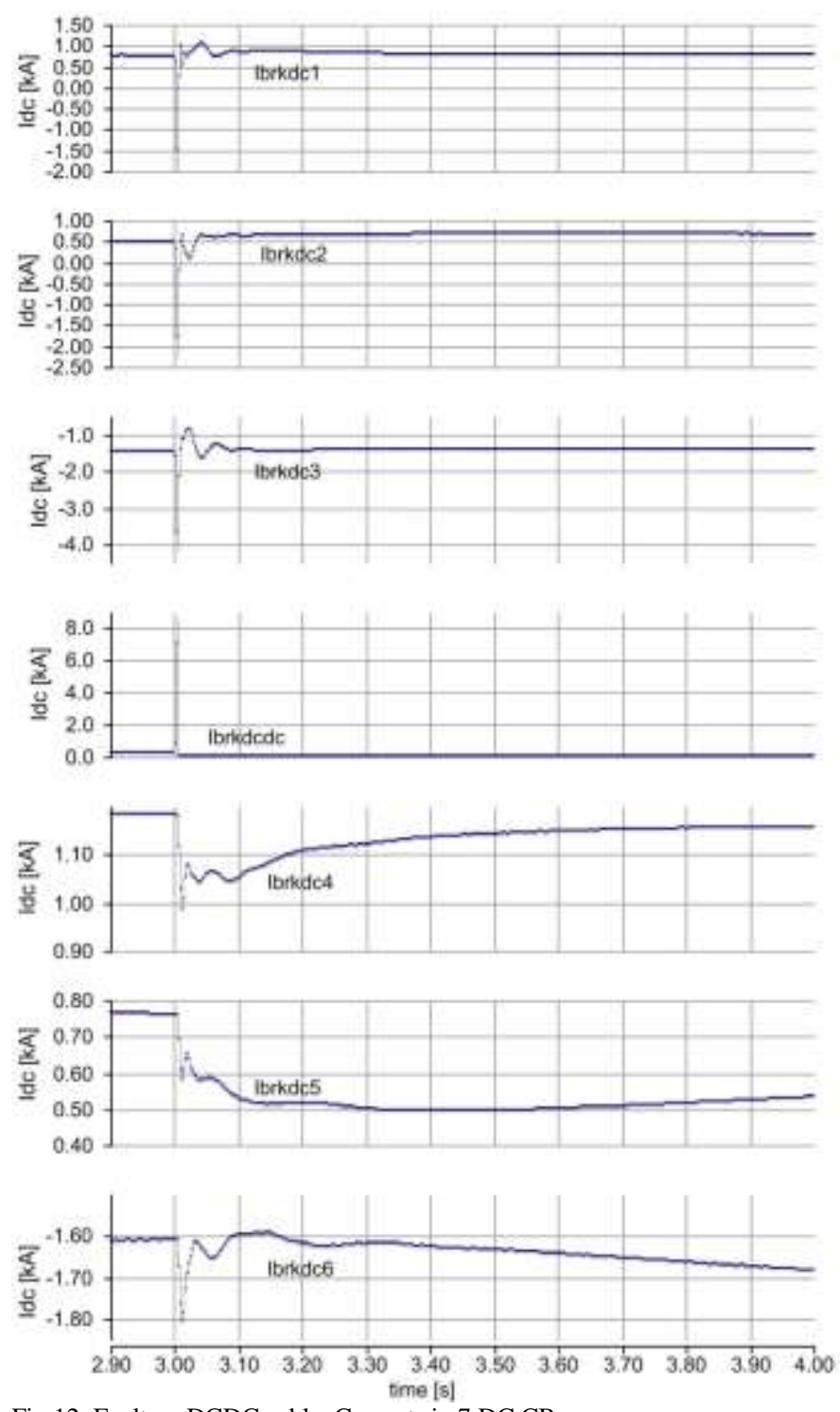

Fig.12. Fault on DCDC cable. Currents in 7 DC CBs.
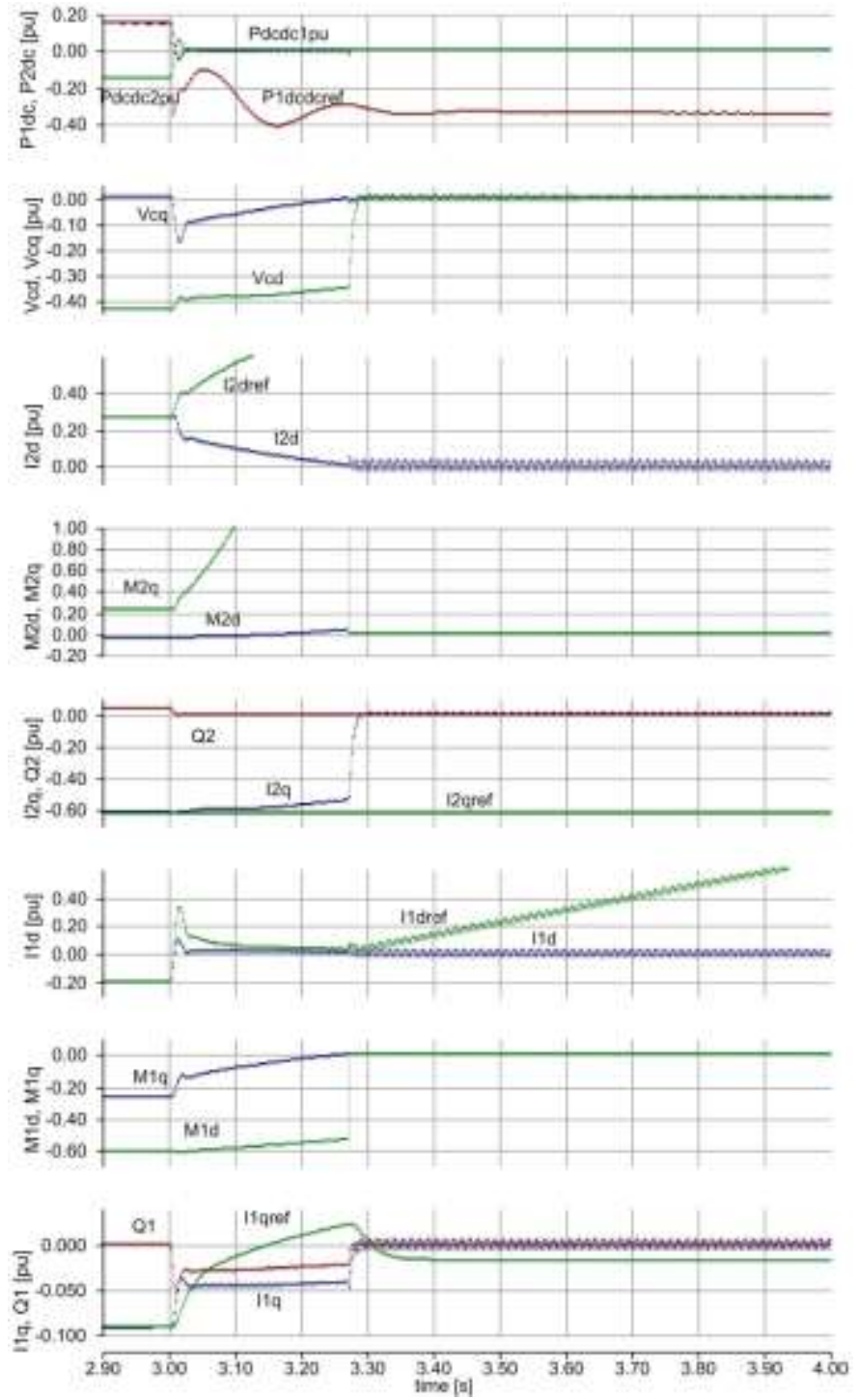

Fig.13. Fault on DCDC cable. Internal DC/DC converter variables.

\section{V.CONCLUSION}

This article presents a DC grid building methodology which ensures robust and accurate protection with moderate costs and simple controls. It is concluded that radial DC systems are well suited for limited-size local DC grids. Radial topologies fully exploit the advantages of fast hybrid DC circuit breakers. On the downside a DC cable fault will imply loss of one VSC converter. The back up protection is also simple with radial systems.

It is proposed to interconnect radial local system using DC cables with DC/DC converters. DC/DC converters enable inherent isolation of DC faults and provide firewall between radial DC grids. It is essential to keep the number of DC/DC converters to minimum.

A full simulation model of $2+4$ terminal DC grid with 2-star points is presented. The PSCAD simulation results confirm advantages of the proposed topology for a range of DC faults. In particular the robustness of protection system is demonstrated for worst case DC faults. The proposed grid control is found to respond excellent to grid contingencies. 


\section{APPENDIX}

TABLE 2 DC/DC CONVERTER DATA

\begin{tabular}{|l|l|}
\hline Power $P_{d c d c}$ & $1000 \mathrm{MW}$ \\
\hline DC Voltage $V_{d c 1}$ & $\pm 250 \mathrm{kV}$ \\
\hline DC Voltage $V_{d c 2}$ & $\pm 320 \mathrm{kV}$ \\
\hline Operating frequency $f$ & $1.0 \mathrm{kHz}$ \\
\hline Number of phases & 4 \\
\hline Filter capacitance $C_{d c l}, C_{d c 2}$ & $10 \mu \mathrm{F}$ \\
\hline Rated Power per phase $(1100 \mathrm{MW}$ design $)$ & $275 \mathrm{MW}$ \\
\hline Rated capacitor voltage $V c[R M S]$ & $380 \mathrm{kV}$ \\
\hline Capacitance $C$ & $67.29 \mu \mathrm{F}$ \\
\hline Inductance $L_{1}$ & $39.94 \mathrm{mH}$ \\
\hline Inductance $L_{2}$ & $41.4 \mathrm{mH}$ \\
\hline
\end{tabular}

TABLE 3 VSC CONVERTER DATA

\begin{tabular}{|l|l|l|}
\hline & $V S C 1-3$ & $V S C 4-6$ \\
\hline Power $P_{v s c}$ & $1000 M \mathrm{~W}$ & $1000 \mathrm{MW}$ \\
\hline DC Voltage $V_{d c l}$ & $\pm 320 \mathrm{kV}$ & $\pm 250 \mathrm{kV}$ \\
\hline DC Capacitance & $68 \mu \mathrm{F}$ & $112 \mu \mathrm{F}$ \\
\hline Series resistance & $0.235 \Omega$ & $0.235 \Omega$ \\
\hline Transformer & $1400 \mathrm{MVA}$ & $1400 \mathrm{MVA}$ \\
\hline Transformer Xt & $0.15 \mathrm{pu}$ & $0.15 \mathrm{pu}$ \\
\hline Series reactor & $0.1 \mathrm{pu}$ & $0.1 \mathrm{pu}$ \\
\hline
\end{tabular}

TABLE 4 AC SYSTEM DATA

\begin{tabular}{|l|l|l|}
\hline \multicolumn{3}{|c|}{ TABLE 4 AC SYSTEM DATA } \\
\hline Voltage & AC $1-2$ & $A C 4-5$ \\
\hline Rac & $400 k V$ & $400 k V$ \\
\hline Xac & $0.399 \Omega$ & $0.399 \Omega$ \\
\hline
\end{tabular}

\section{REFERENCES}

[1] D Jovcic, K.Linden, D. Van Hartem, J.P. Taisne "Feasibility of DC transmission Networks" ISGT Europe, Panel session proceedings, Manchester, December 2011.

[2] CIGRE WG B4.52 "HVDC Grid feasibility study" CIGRE brochure 533, April 2013.

[3] J. Hafner and B. Jacobson, "Proactive Hybrid HVDC Breakers - A key innovation for reliable HVDC grids", CIGRE symposium, Bologna, September 2011

[4] J. Descloux, B. Raison, JB. Curis "Protection strategy for undersea MTDC grids", IEEE PowerTech, Grenoble, 2013.

[5] K. De Kerf, K. Srivastava, M. Reza, D. Bekaert, at all, "Wavelet-based protection strategy for DC faults in multi-terminal VSC HVDC systems," IET Gen. Trans. \& Dist., vol. 5, no. 4, pp. 496-503, 2011

[6] FransDijkhuizen, Bertil Berggren, "Zoning in High Voltage DC (HVDC) Grids using Hybrid DC breaker," EPRI HVDC and FACTS Conferences, USA, August 2013.

[7] M. Taherbaneh, D. Jovcic. J.P. Taisne and S. Nguefeu, "DC Fault Performance and Cost Analysis of DC Grids for Connecting Multiple offshore Wind Farms," Powertech, France, June 2013.

[8] D Jovcic, and L Zhang, "LCL DC/DC converter for DC grids" IEEE Transactions on Power Delivery, vol 28, iss 4, 2013, pp 2071-2079.

[9] W.Lin and D Jovcic "Control strategy for 2-terminal high power LCL DC/DC converter", IEEE PES General meeting, Vancouver, July 2013,

[10] O Gomis-Bellmunt, J Liang, J Ekanayake, R King, N Jenkins "Topologies of multiterminal HVDC-VSC transmission for large offshore wind farms" Electric Power Systems Research 81 (2), 271-281

[11] T K Vrana, Y Yang, D Jovcic, S Dennetière, J Jardini, H Saad, "The CIGRE B4 DC Grid Test System”, ELECTRA issue 270, October 2013, pp 10-19.

[12] W.X. Lin, J. Y. Wen, J. Liang, S. J. Cheng, M. Q. Yao, N. H. Li, “A three-terminal HVDC system to bundle wind farms with conventional power plants" IEEE Transactions on PS, Vol 28 (3),2013, pp 2292-00.

\section{BIOGRAPHIES}

Dragan Jovcic (SM'06, M'00, S'97) obtained a Diploma Engineer degree in Control Engineering from the University of Belgrade, Yugoslavia in 1993 and a $\mathrm{Ph} . D$. degree in Electrical Engineering from the University of Auckland, New Zealand in 1999. He is currently a professor with the University of Aberdeen, Scotland where he has been since 2004. He also worked as a lecturer with
University of Ulster, in the period 2000-2004 and as a design Engineer in the New Zealand power industry in the period 1999-2000. In 2008 he was a visiting professor at McGill University, Canada. His research interests lie in HVDC, FACTS integration of renewable sources and control systems. Professor Jovcic actively contributes in several CIGRE B4 working groups.

Mohsen Taherbaneh graduated in Electronic Engineering from Amirkabir University of Technology, Iran, in 1991 and received his M.Sc. degree in Electronic Engineering from Iran University of Science and Technology, in 1994. He also obtained his Ph.D. from Amirkabir University of Technology in 2010. In 1995, he joined to the Iranian Research Organization for Science and Technology, where he was a research staff until 2010 and then he was an assistant professor from 2010. He is currently a research fellow at the University of Aberdeen, Scotland where he has been since 2012. His research activity is focused on HVDC grid topologies and intelligent systems for power electronic.

Jean-Pierre Taisne was born in France on September 5,1957. He received his dipl-Ing degree in Electrical Enginering from Ecolesupérieured'Electricité in 1980. In 1981 he joined EDF Research Division and was involved in the studies, tests on the HV equipments and commissioning tests of the cross channel HVDC link between France and England and of the Corsica tapping on the SACOI HVDC link between Sardinia and Italy mainland. In 1990 he moved to the Transmission Division, which became RTE in year 2000, and took part in the development of power transformers, phase shifters and static var compensator. He is currently deputy head of the substation department in charge of the converter stations for the new DC interconnections with Spain and Italy.

Samuel Nguefeu (M’04) graduated from ÉcoleSupérieured'Electricité (Supélec) in France in 1991. He received the M.A.Sc. degree (1991) and Ph.D. (Dec. 1993) from Université Pierre et Marie (Paris VI). He worked as Consultant for 2 years before joining THOMSON in 1996. From 1999 to 2005 he worked at EDF R\&D in Power Systems and Power Electronics. In November 2005 he joined the French TSO (RTE) where he is currently involved in FACTS and HVDC projects. 